\title{
Elevated levels of arachidonic acid metabolites in follicular fluid of PCOS patients
}

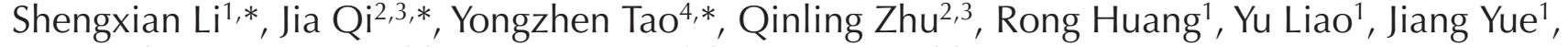 \\ Wei Liu ${ }^{1}$, Hanting Zhao ${ }^{2,3}$, Huiyong Yin ${ }^{4,5,6}$ and Yun Sun ${ }^{2,3}$ \\ ${ }^{1}$ Department of Endocrinology and Metabolism, Renji Hospital, School of Medicine, Shanghai Jiao Tong University, \\ Shanghai, China, ${ }^{2}$ Center for Reproductive Medicine, Renji Hospital, School of Medicine, Shanghai Jiao Tong \\ University, Shanghai, China, ${ }^{3}$ Shanghai Key Laboratory for Assisted Reproduction and Reproductive Genetics, \\ Shanghai, China, ${ }^{4}$ CAS Key Laboratory of Nutrition, Metabolism and Food Safety, Shanghai Institute of Nutrition and \\ Health, Shanghai Institutes for Biological Sciences (SIBS), Chinese Academy of Sciences (CAS), Shanghai, China, \\ ${ }^{5}$ School of Life Science and Technology, ShanghaiTech University, Shanghai, China and ${ }^{6}$ Key Laboratory of Food \\ Safety Risk Assessment, Ministry of Health, Beijing, China
}

Correspondence should be addressed to H Yin or Y Sun; Email: hyyin@sibs.ac.cn or syun163@163.com

*(S Li, J Qi and Y Tao contributed equally to this work)

\begin{abstract}
Polycystic ovary syndrome (PCOS) is the most common endocrine disorder in reproductive-age women usually accompanied by lipid metabolic disorders. However, it remains unknown whether arachidonic acid (AA) and its metabolites in follicular fluid (FF) were altered in PCOS patients. This study was intended to measure the levels of AA and its metabolites in the FF of non-obese PCOS patients that underwent in vitro fertilization (IVF) and to explore the possible causes of the alterations. Thirty-nine non-obese women with PCOS and 30 non-obese women without PCOS were enrolled. AA and its metabolites were measured by liquid chromatographymass spectrometry. The levels of AA metabolites generated via cyclooxygenase-2 (COX-2) pathway and cytochrome P450 epoxygenase pathway but not lipoxygenase (LOX) pathway were significantly higher in the FF of PCOS patients. The metabolites generated via COX-2 pathway were significantly correlated with levels of testosterone and fasting insulin in serum. The in vitro study further demonstrated that insulin but not testosterone could promote the IL-1 $\beta$ and hCG-induced COX-2 expression and prostaglandin E2 $\left(\mathrm{PGE}_{2}\right)$ secretion in primary human granulosa cells. In conclusion, there was an elevation in AA metabolites in FF of PCOS patients. Insulin played a pivotal role in the increased AA metabolites generated via COX-2, which could be interpreted as another novel molecular pathophysiological mechanism of PCOS.

Reproduction (2020) 159 159-169
\end{abstract}

\section{Introduction}

Polycystic ovary syndrome (PCOS) is a complex gynecological and endocrinological disorder affecting 5-10\% of reproductive-age women (Azziz et al. 2004, Li etal.2013, Zhuang etal.2014). The clinical manifestations of PCOS patients include oligomenorrhea or chronic anovulation, hyperandrogenism, and polycystic ovarian morphology. Besides reproductive disorders, PCOS is often accompanied by several metabolic abnormalities, such as obesity, glucose intolerance, insulin resistance, and dyslipidemia.

Arachidonic acid (AA) is metabolized by cyclooxygenase (COX), lipoxygenase (LOX), and cytochrome $\mathrm{P} 450$ epoxygenase ( $\left.\mathrm{P} 450_{\text {epo }}\right)$ pathways that produce other key metabolites. For example, the COX pathway produces several prostaglandins (PGs) that affect oocyte maturation, ovulation, implantation, delivery, and other reproductive processes (Tokugawa et al. 1998, Marions \& Danielsson 1999, Schaiff et al. 2000), whereas three LOX enzymes (5-, 12-, 15-LOXs) metabolize AA to 5-, 12-, and 15-hydroxyeicosatetraenoic acids (5-, 12-, 15-HETEs), respectively.

Follicular fluid (FF) is produced by a complex process that involves the diffusion of serum proteins through the blood-follicle barrier, as well as the secretion of granulosa cells and theca cells (Gerard et al. 2002, Schweigert et al. 2006, Kolialexi et al. 2008, Rodgers \& Irving-Rodgers 2010). FF provides a microenvironment for follicle development and oocyte maturation, and alterations in the composition of FF may affect oocyte development and maturation, fertilization, cleavage, and early embryo formation (Kim et al. 2006, Revelli et al. 2009, Von Wald et al. 2010). Recent studies have addressed the role of FF in the pathogenesis of PCOS (Sorensen et al. 2016, Zhu et al. 2016). Furthermore, a detailed 
analysis of the FF revealed that the concentrations of fatty acids and amino acids were closely related to embryo development (Matoba et al. 2014). Other studies have identified an association between AA metabolites in the FF and oocyte developmental competence (Khajeh et al. 2017); however, the levels of AA and its metabolites in follicular fluid in PCOS patients remain unclear.

Taken collectively, there is a direct correlation between the microenvironment provided by the FF and embryo development. Epidemiological studies have shown that approximately $40 \%$ of women with PCOS are infertile (Teede et al. 2010) and undertake treatment of in vitro fertilization/intracytoplasmic sperm injection (IVF/ICSI). Compared with women without PCOS, a higher number of oocytes are retrieved in women with PCOS receiving controlled ovarian stimulation. However, PCOS patients usually exhibit a relatively lower oocyte utilization rate and high-quality embryo rate (RHQE) (Homburg et al. 1993, Heijnen et al. 2006), and an increased risk of adverse outcomes (Boomsma et al. 2006). Currently, there is no study that measures the levels of $\mathrm{AA}$ and its metabolic profile in the FF of patients with PCOS.

In the present study, we measured and compared $\mathrm{AA}$ and its metabolites in FF of PCOS and non-PCOS patients. Our primary aim in this study was to clarify whether there is an imbalanced state of $\mathrm{AA}$ and its metabolites in the follicular fluid of PCOS. A secondary aim of this study was to elucidate the possible etiology of the imbalanced AA metabolism in PCOS patients.

\section{Materials and methods \\ Participants}

Thirty-nine non-obese $\left(\mathrm{BMI},<25 \mathrm{~kg} / \mathrm{m}^{2}\right)$ patients with PCOS were enrolled according to the revised Rotterdam consensus guidelines (Rotterdam ESHRE/ASRM-Sponsored PCOS Consensus Workshop Group 2004). According to three key clinical features of PCOS, namely oligo-/anovulation(OA), hyperandrogenism (HA) and polycystic ovary morphology (PCOM), the involved patients can be divided into four subtypes $(\mathrm{HA}+\mathrm{OA}, \quad n=5 ; \quad \mathrm{HA}+\mathrm{PCOM}+\mathrm{OA}, \quad n=14$; PCOM+OA, $n=14$; HA+PCOM, $n=6$ ) (Rotterdam ESHRE/ ASRM-Sponsored PCOS Consensus Workshop Group 2004). Thirty non-obese patients without PCOS were enrolled as nonPCOS patients; these patients took IVF because of tubal factors (unilateral or bilateral tubal obstruction, adhesion, unilateral or bilateral salpingectomy, or tubal ligation). All patients were 20-35 years old with a history of infertility for over 1 year. The following patients were excluded from the study: (1) women who underwent unilateral oophorectomy; (2) women with a history of a uterine abnormality (malformed uterus, adenomyosis, submucous myoma, or intrauterine adhesion); (3) women or their partners with a diagnosis of an abnormal chromosome karyotype; and (4) women with a history of recurrent spontaneous abortions.

All procedures were performed at the Center for Reproductive Medicine, Renji Hospital, School of Medicine,
Shanghai Jiao Tong University. Written informed consent was obtained, and approval of the ethics protocol was granted from the Ethics Committee of Renji Hospital (Ethical Authorization Number: 2015030308).

\section{Controlled ovarian hyperstimulation and FF collection}

All patients were enrolled in a standardized gonadotropinreleasing hormone $(\mathrm{GnRH})$ antagonist protocol (Shi et al. 2014, Zhu et al. 2016). In brief, patients received recombinant follicle-stimulating hormone ( $r F S H$, Gonal-f; Merck Serono) on day 3 of spontaneous menses or day 3 of the cycle induced by oral contraceptive pills. Patients received the GnRH antagonist Cetrorelix (Merck Serono) at a daily dose of 250 $\mu \mathrm{g}$ by s.c. injection when there was at least one follicle with a mean diameter of $\geq 12 \mathrm{~mm}$ until the desired stage of follicular development was reached. Patients received human chorionic gonadotropin (hCG, Lvzhu, Zhuhai, China) to initiate ovulation when there was at least one leading follicle with a diameter of $\geq 18 \mathrm{~mm}$. Transvaginal ultrasound-guided oocyte retrieval was performed $36 \mathrm{~h}$ later. The FF from the first leading oocytes without contaminating blood was collected immediately from the dominant follicles. The FF was centrifuged at $200 \boldsymbol{g}$ for 5 min at room temperature, and $2 \mathrm{~mL}$ of the supernatant was collected and stored at $-80^{\circ} \mathrm{C}$ until further analysis.

\section{Clinical analyses}

\section{Hormone measurements}

The blood samples were collected before gonadotropin use. The basal serum hormonal profiles of luteinizing hormone $(\mathrm{LH})$, follicle-stimulating hormone ( $\mathrm{FSH})$, testosterone, estradiol $\left(\mathrm{E}_{2}\right)$, prolactin $(\mathrm{PRL})$, and anti-Müllerian hormone $(\mathrm{AMH})$ were determined using chemiluminescent assay kits (Beckman Access Health Company, Chaska, MN, USA). Serum fasting insulin and fasting plasma glucose were measured using a chemiluminescence assay kit (Beckman Access Health Co) and a standard glucose oxidase method (Roche), respectively. The homeostasis model of assessment for insulin resistance index (HOMA-IR) was calculated as fasting serum insulin $(\mu \mathrm{IU} / \mathrm{mL}) \times$ fasting plasma glucose $(\mathrm{mmol} / \mathrm{L}) / 22.5)$.

\section{AA metabolite measurements}

Standards and deuterated standards of $\mathrm{AA}$, including $\mathrm{PGD}_{2}$, $\mathrm{PGE}_{2}, \mathrm{PGF}_{2 \alpha^{\prime}} \mathrm{PGI}_{2}$, thromboxane B2 $\left(\mathrm{TXB}_{2}\right), 5$-HETE, 12-HETE, 15-HETE, and epoxyeicosatrienoic acids (EETs), were purchased from Cayman Chemicals. The solvents for sample preparation and mass spectrometry (MS), such as methanol, chloroform, and water, were purchased from Burdick \& Jackson (Muskegon, MI, USA). Other HPLC quality solvents, such as methanol, 2-propanol, hexane, and acetonitrile, were purchased from either Fisher Chemical (Phillipsburg, NJ, USA) or EM Science (Gibbstown, NJ, USA).

Lipids were extracted from FF as previously described with minor modifications (Han et al. 2004, 2005), and AA metabolites were analyzed by a metabolomic method (Deems et al. 2007, Buczynski et al. 2009, Yang et al. 2009, Huang et al. 2014, Lu et al. 2017). After adding the mixture 
of deuterated internal standards $(0.5 \mathrm{ng} / \mu \mathrm{L})$ to $500 \mu \mathrm{L}$ of the $\mathrm{FF}$, the $\mathrm{pH}$ of the solution was adjusted to 3.0 using 1 $\mathrm{N} \mathrm{HCl}$. Liquid-liquid extraction of the mixture was carried out twice using hexane:methyl t-butyl ether (50:50, v/v). The samples were separated on a Phenomenex Kinetix C18 column (particle size, $3 \mu \mathrm{m}$; length $\times$ internal diameter, $100 \times 2.1 \mathrm{~mm}$ ) using a Thermo Accela HPLC system at a flow rate of $0.4 \mathrm{~mL} / \mathrm{min}$ using a gradient of mobile phase $A$ (water:acetonitrile:formic acid 63:37:0.02, v/v/v) and mobile phase B (acetonitrile:isopropanol 50:50, v/v). MS analysis was carried out on a TSQ Vantage triple quadrupole mass spectrometer (San Jose, CA, USA). The mass spectrometer was operated in the negative-ion mode using multiple-reaction monitoring. Data acquisition and analysis were performed using Xcalibur software, version 2.0. The limit of detection and coefficient variations of our method are comparable to those reported in the literature (Huang et al. 2014, Wang et al. 2014). Specifically, the limit of sensitivity for most AA metabolites is in the $\mathrm{pg} / \mathrm{mL}$ range. All the metabolites were detected with a precision of coefficient variation less than $20 \%$ and accuracy of relative error less than $25 \%$.

\section{Isolation and culture of primary granulosa cells}

The granulosa cells (GCs) were isolated from the follicular fluid as described previously (Zhu et al. 2016). Briefly, follicular fluid from each patient was pooled and centrifuged. The purified pellet was obtained by density centrifugation with Ficoll-Paque (GE Healthcare) and then dispersed in $0.1 \%$ hyaluronidase (Sigma) at $37^{\circ} \mathrm{C}$ for $10 \mathrm{~min}$. The cells were then cultured in Dulbecco's modified Eagle medium/Ham's F12 with 10\% fetal bovine serum (Gibco), $100 \mathrm{U} / \mathrm{mL}$ penicillin (Invitrogen, Life Technologies) and $100 \mu \mathrm{g} / \mathrm{mL}$ streptomycin sulfate (Invitrogen, Life Technologies). The viable cells were seeded at $7 \times 10^{5}$ cells per well in a six-well culture plate. Three days after culture, the cells were seeded in phenol red and serum-free medium. The cells were incubated with insulin (100 nM), testosterone $(100 \mathrm{nM})$, hCG $(10 \mathrm{IU} / \mathrm{L})$ and interleukin $1 \beta(\mathrm{IL}-1 \beta, 1 \mathrm{ng} / \mathrm{mL})$ for $24 \mathrm{~h}$.

\section{Reverse transcription and real-time quantitative PCR}

Total RNA from cultured granulosa cells was extracted using a total RNA Kit (Foregene) according to manufacturer's instructions and was reverse transcribed to cDNA using the PrimeScript $\mathbb{R}$ RT kit (TaKaRa) with appropriate controls. Quantitative real-time PCR was performed and analyzed with $\mathrm{ABI}$ Prism System (Applied Biosystems) using SYBR $\mathbb{R}$ Premix (TaKaRa) in triplicate. Relative mRNA expression was calculated by the comparative cycle threshold method $(\Delta \Delta \mathrm{Ct})$ with ACTB as the housekeeping gene. The primer sequences used of targeting genes were as follows:

COX-2: 5'-CTGGCGCTCAGCCATACAG-3' (forward) and 5'-CGCACTTATACTGGTCAAATCCC-3' (reverse); ACTB: 5'-GGGAAATCGTGCGTGACATTAAG-3' (forward) and 5'-TGTGTTGGCGTACAGGTCTTTG-3' (reverse)

\section{Western blot analysis}

Total protein was extracted from cells using an ice-cold radioimmunoprecipitation assay lysis buffer (Cwbio) containing a phosphatase inhibitor (Active Motif) and a protease inhibitor cocktail (Roche). Protein (40 $\mu$ g) from each sample was electrophoresed in a 10\% SDS-PAGE gel and then transferred onto a nitrocellulose blot. After $1 \mathrm{~h}$ of blocking with $5 \%$ nonfat milk, the blot was incubated overnight at $4{ }^{\circ} \mathrm{C}$ with antibodies against COX-2 $(1: 1000,320 \mu \mathrm{g} / \mathrm{L}$, Poteintech) and ACTB (1:1000, $430 \mu \mathrm{g} / \mathrm{L}$, Poteintech). On the second day, the blot was washed and then incubated with the respective secondary antibody conjugated to horseradish peroxidase (Proteintech) for $1 \mathrm{~h}$. Bands with peroxidase activity were detected by an enhanced chemiluminescent detection kit (Merck Millipore) and visualized with a G-Box chemiluminescence image capture system (Syngene).

\section{$P G E_{2}$ measurement}

The culture medium of granulosa cells was collected. $\mathrm{PGE}_{2}$ was measured using PGE $_{2}$ ELISA Kit (No. 514010, Cayman) following manufacturer's instructions. The intra-assay variation at $500 \mathrm{pg} / \mathrm{mL}$ and $62.5 \mathrm{pg} / \mathrm{mL}$ were 3.9 and 6.6 respectively. The inter-assay variation at $500 \mathrm{pg} / \mathrm{mL}$ and $62.5 \mathrm{pg} / \mathrm{mL}$ were 6.4 and 15.5 respectively.

\section{Statistical analyses}

Data were presented as means \pm S.D. The Kolmogorov-Smirnov test was used to determine whether the continuous variables fit a normal distribution. The unpaired $t$-test was used to assess the differences in normally distributed variables. The non-parametric Mann-Whitney test was used for non-normal distribution variables between PCOS and non-PCOS groups. The correlation between the variables was performed using the Pearson analysis. Multiple linear regression analysis was performed to investigate the correlations between the serum testosterone, fasting insulin and AA metabolites. The Statistical Package for Social Sciences (SPSS, version 18.0 for Windows) was used for data analysis.

\section{Results}

\section{Clinical characteristics of patients with PCOS that underwent IVF}

The basal testosterone $(1.30 \pm 0.83$ vs $0.75 \pm 0.45$ $\mathrm{nmol} / \mathrm{L}, P<0.05)$, basal LH $(8.01 \pm 4.94$ vs $4.48 \pm 1.44$ IU/L, $P<0.001)$ and fasting insulin levels $(14.17 \pm 13.85$ vs $6.13 \pm 1.83 \mathrm{mIU} / \mathrm{L}, P<0.05)$ in the serum were significantly higher $(P<0.05)$ in PCOS patients than in non-PCOS patients. Age $(27.85 \pm 3.86$ vs $27.33 \pm 3.49$ years) and BMI (22.98 \pm 3.30 vs $20.53 \pm 2.65$ years) were comparable in PCOS and non-PCOS patients, and there were no statistically significant differences in the $\mathrm{FSH}$, $\mathrm{E}_{2}, \mathrm{AMH}$ and fasting glucose levels between groups. The fasting insulin, basal testosterone and basal LH levels in the FF were also significantly higher in PCOS patients 
than in non-PCOS patients (Supplementary Table 1, see section on supplementary materials given at the end of this article). In non-PCOS patients, the average number of retrieved oocytes is $13.29 \pm 1.26$, while in PCOS patients the average number of retrieved oocytes is $16.90 \pm 1.15$ ( $P<0.05$ vs non-PCOS).

\section{Changes in the levels of $A A$ and its metabolites in FF from PCOS patients that underwent IVF}

Figure 1 shows representative liquid chromatographymass spectrometry (LC-MS) of the FF from patients that underwent IVF. Complete LC-MS lipidomic datasets were obtained for the FF of patients with and without PCOS. The levels of free AA (F-C 20:4 n-6) and total AA (T-C 20:4 n-6) in follicular fluid from PCOS patients were comparable with non-PCOS group (Fig. 2 ). There was a significant elevation in the levels of AA metabolites generated via P450 ${ }_{\text {eро }}$ (8,9-DHET and 11,12 -DHET) in PCOS group than in non-PCOS group
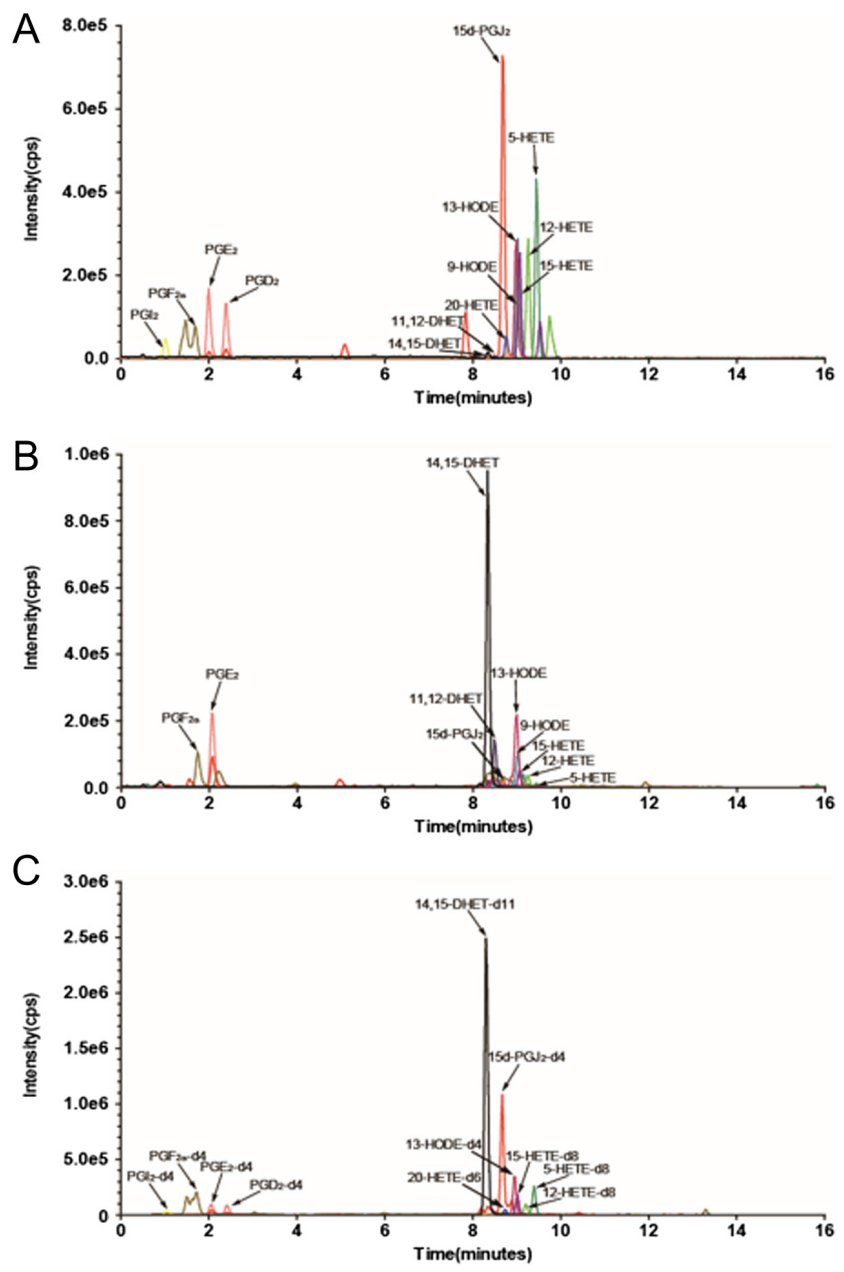

Figure 1 Representative LC-MS chromatograms of follicular fluid (FF) specimens from patients that underwent IVF. Chromatograms of arachidonic acid metabolites in a standard mixture (A), FF from a PCOS patient (B), and an internal standard (C).
(Fig. 2). The levels of AA metabolites generated via the COX pathway $\left(\mathrm{PGI}_{2}, \mathrm{PGE}_{2}, \mathrm{PGD}_{2}, \mathrm{PGF}_{2 \alpha}\right.$ and $\left.\mathrm{TXB}_{2}\right)$ were significantly higher $(P<0.05)$ in patients of PCOS group than in those of the non-PCOS group (Fig. 2). The levels of $P G J_{2}$ and 15-deoxy- $\Delta 12,14$-prostaglandin $\mathrm{J}_{2}(15 \mathrm{~d}$ $P G J_{2}$ ), which were metabolized from $\mathrm{PGD}_{2}$, were also significantly higher $(P<0.05)$ in patients of the PCOS group than in those of the non-PCOS group (Fig. 2). There were no statistically significant differences in the levels of metabolites generated via the LOX pathways between groups.

\section{Correlation between the $A A$ metabolites, testosterone and fasting insulin}

In Pearson's correlation tests, the levels of AA metabolites generated via $\mathrm{P}_{450}{ }_{\text {eро }}$ (8,9-DHET, 11,12-DHET, and 14,15-DHET) in follicular fluid, the levels of AA metabolites generated via LOX (5-HETE and 15-HETE) in follicular fluid and the levels of AA metabolites generated via COX $\left(\mathrm{PGJ}_{2}, \mathrm{PGE}_{2}, \mathrm{PGF}_{2 \alpha^{\prime}}\right.$ and $\left.\mathrm{TXB}_{2}\right)$ in follicular fluid were significantly correlated with serum basal testosterone levels. The levels of $A A$ metabolites generated via COX $\left(\mathrm{PG}_{2}, \mathrm{PGE}_{2}, \mathrm{PGF}_{2 \alpha^{\prime}}\right.$ and $\left.\mathrm{TXB}_{2}\right)$ were significantly correlated with serum fasting insulin levels.

Further multivariant linear regression analysis confirmed that only AA metabolites generated via $\operatorname{COX}\left(\mathrm{PG}_{2}, \mathrm{PGE}_{2}\right.$, and $\left.\mathrm{PGF}_{2 \alpha}\right)$ in follicular fluid were significantly associated with basal testosterone after adjusting for basal $\mathrm{LH}$ and $\mathrm{BMI}$. As for the associations between AA metabolites and fasting insulin, significant correlations were also observed in $\mathrm{AA}$ metabolites generated via $\mathrm{COX}\left(\mathrm{PG}_{2}, \mathrm{PGE}_{2}\right.$, and $\left.\mathrm{PGF}_{2 \alpha}\right)$ adjusting for basal testosterone and BMI (Table 1).

Then the correlation between the levels of $\mathrm{AA}$ metabolites generated via $\mathrm{P}_{450} \mathrm{epo} \mathrm{LOX}$, and COX in follicular fluid with serum basal testosterone and fasting insulin levels were also analyzed in PCOS group and non-PCOS group by Pearson's correlation tests. The levels of $\mathrm{TXB}_{2}$ generated via COX in follicular fluid were significantly correlated with serum basal testosterone levels in non-PCOS group. The levels of $\mathrm{PG}{ }_{2}$ generated via COX in follicular fluid were significantly correlated with serum basal testosterone levels in PCOS group. The levels of AA metabolites generated via $\mathrm{P}_{450}$ epo $(5,6-$ EET, 11,12-EET) in follicular fluid, and the levels of AA metabolites generated via COX $\left(15 \mathrm{~d}-\mathrm{PG}_{2}, \mathrm{PGE}_{2}\right.$, and $\mathrm{PGF}_{2 \alpha}$ ) in follicular fluid were significantly correlated with serum fasting insulin levels in non-PCOS group. The levels of AA metabolites generated via $\mathrm{COX}\left(\mathrm{PG}_{2}\right.$, $\mathrm{PGD}_{2}$, and $\mathrm{PGE}_{2}$ ) in follicular fluid were significantly correlated with serum fasting insulin levels in PCOS group. Multivariant linear regression analysis showed that AA metabolites generated via COX $\left(15 \mathrm{~d}-\mathrm{PG}_{2}\right.$, $\mathrm{PGE}_{2}$ and $\mathrm{PGF}_{2 \alpha}$ ) and via $\mathrm{P}_{450} 0_{\text {eро }}(5,6-\mathrm{EET})$ in nonPCOS group, and only AA metabolites generated via COX $\left(\mathrm{PG}_{2}, \mathrm{PGD}_{2}\right.$, and $\left.\mathrm{PGE}_{2}\right)$ in $\mathrm{PCOS}$ group were 

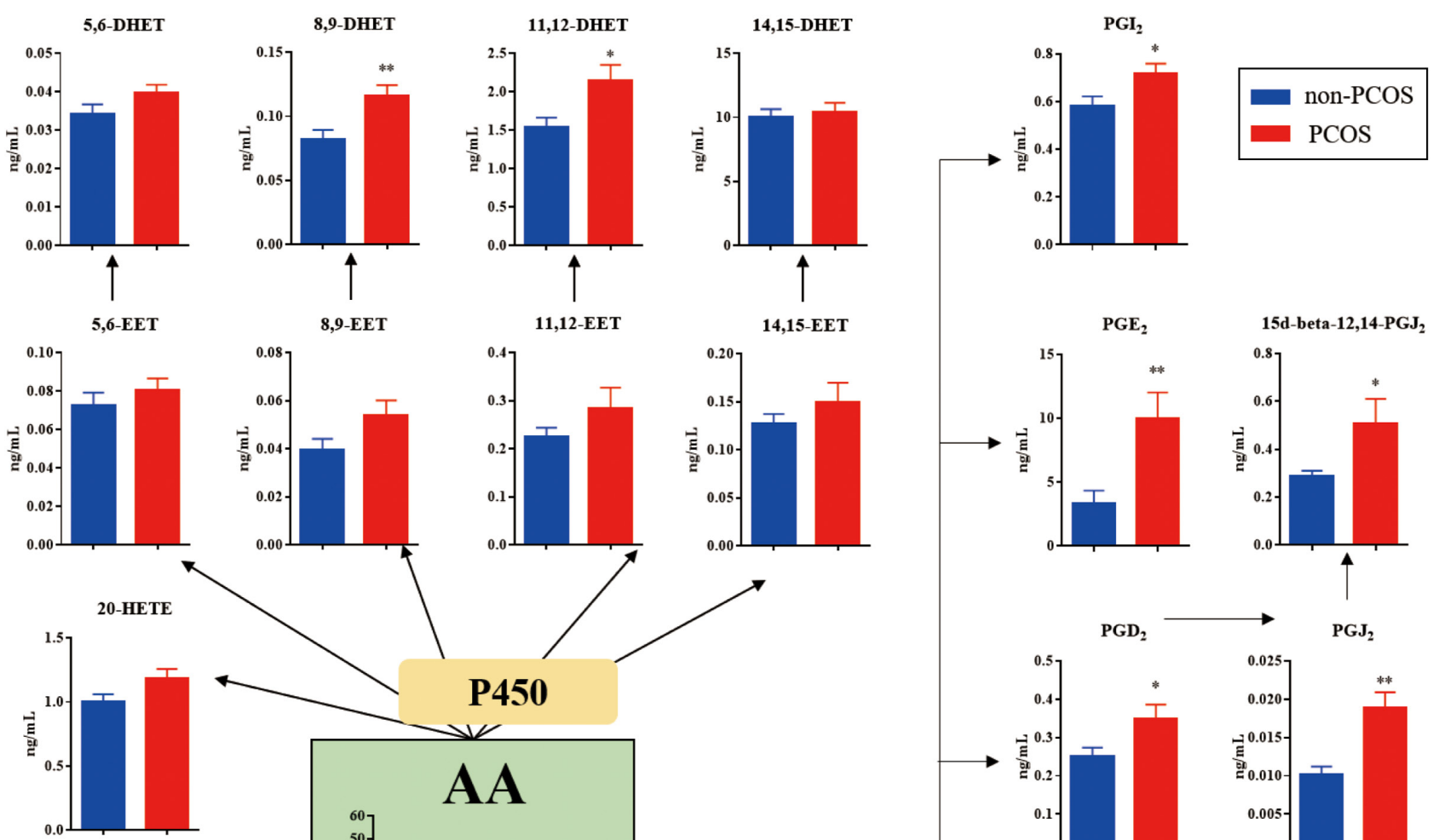

$\mathrm{PGE}_{2}$

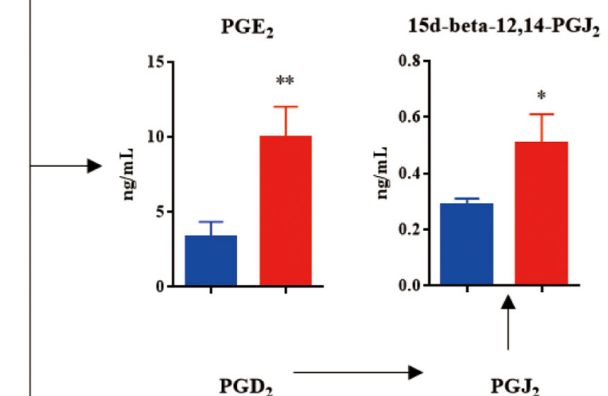

15d-beta-12,14-PGJ
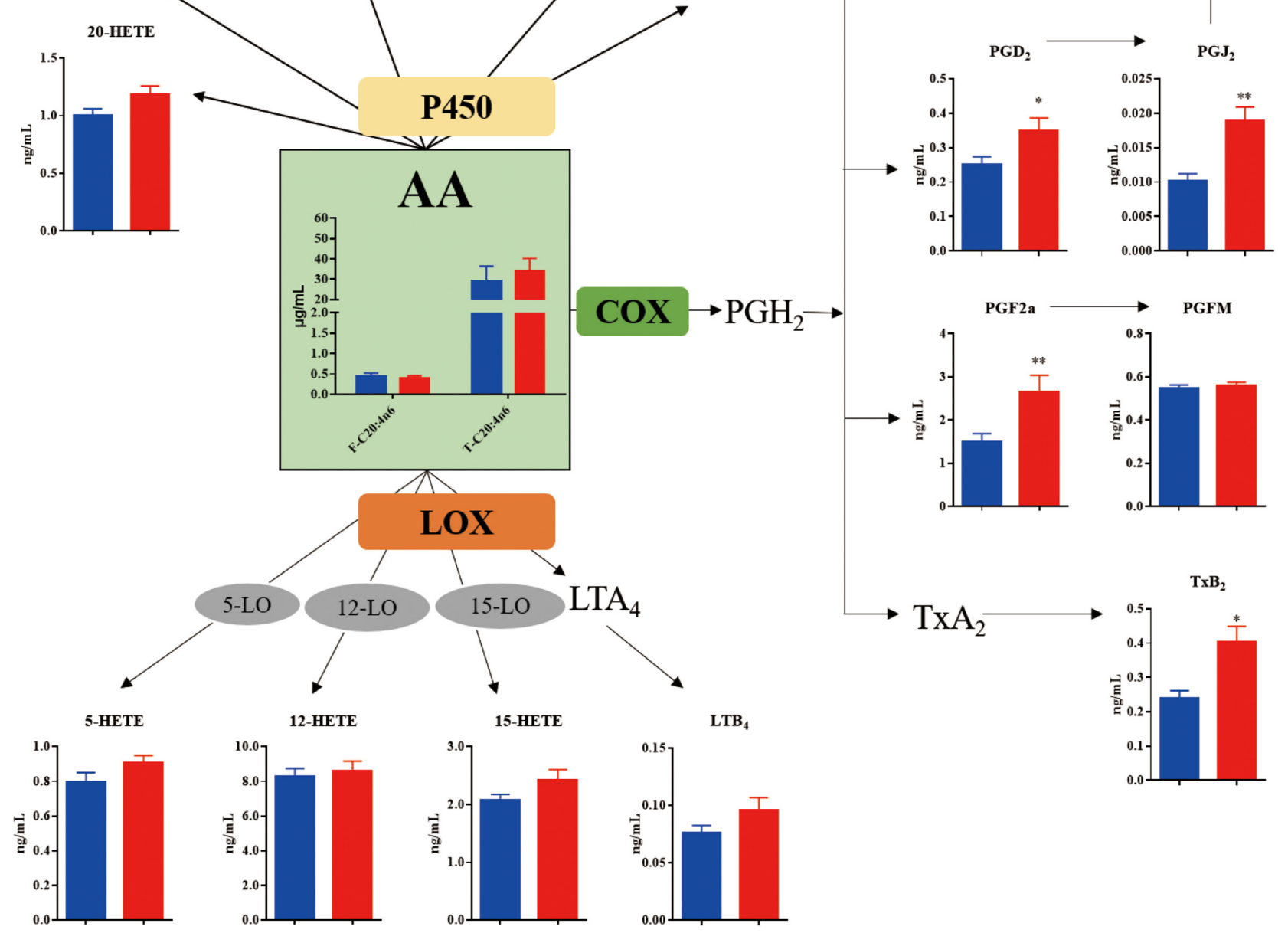

Figure 2 Levels of AA and its metabolites generated in the FF from patients with PCOS and without PCOS (non-PCOS). COX, cyclooxygenase; $\mathrm{PGD}_{2}$, prostaglandin $\mathrm{D}_{2} ; \mathrm{PGJ}_{2}$, prostaglandin $\mathrm{J}_{2} ; 15 \mathrm{~d}-\mathrm{PG}_{2}, 15$-deoxy- $\Delta^{12,14}$-prostaglandin $\mathrm{J}_{2} ; \mathrm{PGE}_{2}$, prostaglandin $\mathrm{E}_{2} ; \mathrm{PGF}_{2 \alpha^{\prime}}$ prostaglandin $\mathrm{F}_{2 \text { alphai }}$; PGFM, prostaglandin $\mathrm{F}$ metabolite; $\mathrm{PGI}_{2}$, prostaglandin $\mathrm{I}_{2}$; and $\mathrm{TXB}_{2}$, thromboxane $\mathrm{B}_{2}$; LOX, lipoxidase; $\mathrm{P} 450_{\text {epo }}$ cytochrome P450 epoxygenase; EETs, epoxyeicosatrienoic acids; HETEs, hydroxyeicosatetraenoic acids. Data are mean \pm S.E.M. $n=30$ for non-PCOS and $n=39$ for PCOS. ${ }^{*} P<0.05,{ }^{* *} P<0.01$ compared with group non-PCOS. The blue column represents non-PCOS and the red column represents PCOS. 
Table 1 Correlation between AA metabolites, testosterone and fasting insulin.

\begin{tabular}{|c|c|c|c|c|c|c|}
\hline & \multicolumn{3}{|c|}{ Basal testosterone $(\mathrm{nmol} / \mathrm{L})$} & \multicolumn{3}{|c|}{ Fasting insulin $(\mu \mathrm{IU} / \mathrm{L})$} \\
\hline & $r^{*}$ & $P^{*}$ & $P^{+}$ & $r$ & $P^{*}$ & $P^{\dagger}$ \\
\hline \multicolumn{7}{|l|}{ P450 metabolites } \\
\hline 5,6-EET & -0.063 & 0.622 & & -0.118 & 0.366 & \\
\hline 8,9-EET & -0.038 & 0.764 & & -0.079 & 0.543 & \\
\hline $11,12-\mathrm{EET}$ & -0.037 & 0.770 & & -0.113 & 0.385 & \\
\hline $14,15-\mathrm{EET}$ & -0.103 & 0.419 & & -0.038 & 0.770 & \\
\hline 5,6-DHET & 0.195 & 0.122 & & -0.038 & 0.771 & \\
\hline 8,9-DHET & 0.283 & 0.024 & 0.313 & -0.079 & 0.543 & \\
\hline 11,12-DHET & 0.321 & 0.010 & 0.675 & -0.119 & 0.361 & \\
\hline 14,15-DHET & 0.252 & 0.045 & 0.550 & -0.192 & 0.138 & \\
\hline 20-HETE & 0.227 & 0.072 & & 0.132 & 0.310 & \\
\hline \multicolumn{7}{|l|}{ LOX metabolites } \\
\hline 5-HETE & 0.272 & 0.030 & 0.966 & 0.020 & 0.878 & \\
\hline 12-HETE & 0.094 & 0.459 & & -0.099 & 0.446 & \\
\hline 15-HETE & 0.266 & 0.033 & 0.299 & 0.248 & 0.054 & \\
\hline LTB4 & -0.027 & 0.830 & & 0.020 & 0.879 & \\
\hline \multicolumn{7}{|l|}{ COX metabolites } \\
\hline 15-d-beta-12,14PGJ ${ }_{2}$ & 0.020 & 0.876 & & 0.057 & 0.660 & \\
\hline$P G J_{2}$ & 0.400 & 0.001 & 0.032 & 0.431 & 0.001 & 0.013 \\
\hline $\mathrm{PGD}_{2}$ & 0.206 & 0.102 & & 0.386 & 0.002 & 0.520 \\
\hline $\mathrm{PGE}_{2}{ }^{2}$ & 0.328 & 0.008 & 0.027 & 0.455 & 0.000 & 0.004 \\
\hline $\mathrm{PGF}_{2 \mathrm{a}}$ & 0.292 & 0.019 & 0.031 & 0.373 & 0.003 & 0.009 \\
\hline 8-iso-PGF $2 \mathrm{a}$ & -0.072 & 0.570 & & 0.040 & 0.757 & \\
\hline PGFM & 0.139 & 0.272 & & 0.091 & 0.483 & \\
\hline $\mathrm{PGI}_{2}$ & 0.167 & 0.187 & & 0.286 & 0.025 & 0.829 \\
\hline $\mathrm{TXB}_{2}$ & 0.327 & 0.008 & 0.455 & -0.083 & 0.527 & \\
\hline
\end{tabular}

*Pearson's correlation tests. ${ }^{\dagger}$ Multivariant linear regression model.

significantly associated with basal fasting insulin after adjusting for basal $\mathrm{LH}$ and $\mathrm{BMI}$ (Table 2).

\section{Effects of testosterone and insulin on hCG- and IL-1ק- induced COX-2 expression}

The primary granulosa cells were obtained from nonPCOS patients. Treatment of human primary granulosa cells with IL-1 $\beta$ and hCG for $24 \mathrm{~h}$ upregulated COX-2 expression significantly (Fig. $3 \mathrm{~A}$ and $\mathrm{B}$ ) and the coexistence of IL-1 $\beta$ and hCG could further increase the expression of COX-2. Insulin alone could not induce the expression of COX-2 but could further upregulate the induction role of IL-1 $\beta$ and hCG (Fig. 3A). Testosterone alone could not induce the expression of COX-2, and it had no effect on the induction role of IL-1 $\beta$ and hCG either (Fig. 3B). The concentrations of COX-2 protein were further measured by Western blot, and the change of the protein level was same as the mRNA expression measured by real-time PCR (Fig. 3C and D).

\section{Effects of testosterone and insulin on hCG and IL-1及- induced $P G E_{2}$ secretion}

The same treatment of human primary granulosa cells with testosterone and insulin with or without IL-1 $\beta$ and hCG for $24 \mathrm{~h}$ described as before. Insulin and testosterone alone could not increase the concentration of $\mathrm{PGE}_{2}$ in the culture medium, while IL-1 $\beta$ and hCG alone could $(P<0.05)$. IL-1 $\beta$ combined with hCG could further increase the secretion of $\mathrm{PGE}_{2}$ by the granulosa cells cultured in vitro. Only insulin, not testosterone, could further increase the stimulation role of IL-1 $\beta$ combined with hCG (Fig. 3E and F).

\section{Discussion}

More than $40 \%$ of PCOS patients are infertile and require IVF/ICSI (Teede et al. 2010). Although the number of retrieved oocytes is higher in PCOS patients who undergo controlled ovarian stimulation, the oocyte utilization rate does not increase accordingly and IVF/ ICSI outcomes are unsatisfactory (Boomsma et al. 2006, Heijnen et al. 2006). Emerging evidence suggests that FF provides a microenvironment for oocyte development and maturation, and the FF components might influence the oocyte development (Robker et al. 2009, Jungheim et al. 2011, Leroy et al. 2011). AA-derived metabolites, especially PGs, which play key roles in oocyte maturation, cumulus expansion and ovulation. To our knowledge, the profile of AA-derived metabolites in FF in PCOS patients has never been examined. Testosterone or insulin, or both was involved in regulating the concentration of AA-derived metabolites in human FF at the moment has not been reported either. This study provides an extensive profile of follicular AA metabolism in PCOS patients. We evaluated the AA metabolites via COX, $\mathrm{P} 450_{\mathrm{epo}^{\prime}}$ and LOX in FF and first demonstrated the elevation of $\mathrm{AA}$ metabolites via $\mathrm{COX}\left(\mathrm{PGI}_{2}, \mathrm{PGE}_{2}\right.$, $\left.\mathrm{PGD}_{2}, \mathrm{PGF}_{2 \alpha^{\prime}}, \mathrm{TXB}_{2}, \mathrm{PG}\right)_{2}$, and $15 \mathrm{~d}-\mathrm{PGJ}_{2}$ ) and $\mathrm{P}^{2} 50_{\text {eро }}$ 
Table 2 Correlation between AA metabolites, testosterone and fasting insulin in non-PCOS and PCOS patients separately.

\begin{tabular}{|c|c|c|c|c|c|c|c|c|c|c|c|c|}
\hline & \multicolumn{6}{|c|}{ Basal testosterone (nmol/L) } & \multicolumn{6}{|c|}{ Fasting insulin $(\mu \mathrm{I} U / \mathrm{L})$} \\
\hline & $r^{*}$ & $P^{*}$ & $P^{* \ddagger}$ & $r^{\dagger}$ & $P^{\dagger}$ & $P^{+\neq}$ & $r^{*}$ & $P^{*}$ & $P^{* \ddagger}$ & $r^{+}$ & $P^{+}$ & $P^{\ddagger \ddagger}$ \\
\hline \multicolumn{13}{|l|}{ P450 metabolites } \\
\hline 5,6-EET & -0.047 & 0.821 & & -0.115 & 0.492 & & 0.419 & 0.033 & 0.031 & -0.244 & 0.158 & \\
\hline 8,9-EET & -0.244 & 0.231 & & -0.120 & 0.472 & & 0.019 & 0.928 & & -0.213 & 0.220 & \\
\hline $11,12-\mathrm{EET}$ & 0.248 & 0.222 & & -0.139 & 0.404 & & 0.439 & 0.025 & 0.094 & -0.206 & 0.235 & \\
\hline 14,15-EET & -0.203 & 0.320 & & -0.157 & 0.345 & & 0.181 & 0.377 & & -0.113 & 0.516 & \\
\hline 5,6-DHET & -0.127 & 0.536 & & 0.245 & 0.139 & & 0.331 & 0.099 & & -0.200 & 0.249 & \\
\hline 8,9-DHET & -0.083 & 0.686 & & 0.260 & 0.116 & & 0.043 & 0.834 & & -0.265 & 0.124 & \\
\hline 11,12-DHET & -0.047 & 0.820 & & 0.297 & 0.070 & & 0.065 & 0.751 & & -0.269 & 0.118 & \\
\hline 14,15-DHET & 0.100 & 0.627 & & 0.275 & 0.095 & & -0.074 & 0.719 & & -0.288 & 0.094 & \\
\hline 20-HETE & 0.298 & 0.140 & & 0.124 & 0.460 & & 0.059 & 0.776 & & 0.058 & 0.742 & \\
\hline \multicolumn{13}{|l|}{ LOX metabolites } \\
\hline 5-HETE & 0.104 & 0.613 & & 0.237 & 0.152 & & 0.080 & 0.698 & & -0.114 & 0.516 & \\
\hline 12-HETE & -0.022 & 0.914 & & 0.105 & 0.531 & & 0.144 & 0.484 & & -0.162 & 0.352 & \\
\hline 15-HETE & 0.102 & 0.620 & & 0.239 & 0.148 & & 0.168 & 0.413 & & 0.203 & 0.242 & \\
\hline LTB4 & -0.192 & 0.349 & & -0.083 & 0.621 & & 0.354 & 0.076 & & -0.085 & 0.629 & \\
\hline \multicolumn{13}{|l|}{ COX metabolites } \\
\hline 15-d-beta-12,14PG) ${ }_{2}$ & 0.329 & 0.101 & & -0.094 & 0.576 & & 0.539 & 0.004 & 0.011 & -0.041 & 0.815 & \\
\hline $\mathrm{PGJ}_{2}$ & 0.154 & 0.453 & & 0.322 & 0.049 & 0.068 & 0.154 & 0.451 & & 0.356 & 0.036 & 0.025 \\
\hline $\mathrm{PGD}_{2}$ & 0.279 & 0.167 & & 0.092 & 0.583 & & 0.343 & 0.086 & & 0.344 & 0.043 & 0.006 \\
\hline $\mathrm{PGE}_{2}$ & 0.143 & 0.485 & & 0.261 & 0.114 & & 0.548 & 0.004 & 0.010 & 0.391 & 0.020 & 0.003 \\
\hline $\mathrm{PGF}_{2 \mathrm{a}}$ & 0.136 & 0.508 & & 0.215 & 0.194 & & 0.471 & 0.015 & 0.044 & 0.293 & 0.088 & \\
\hline 8-iso-PGF 2 a & 0.091 & 0.659 & & -0.165 & 0.322 & & 0.195 & 0.339 & & 0.022 & 0.899 & \\
\hline PGFM & 0.123 & 0.548 & & 0.105 & 0.529 & & 0.271 & 0.181 & & 0.035 & 0.843 & \\
\hline $\mathrm{PGI}_{2}$ & 0.329 & 0.101 & & 0.015 & 0.927 & & 0.222 & 0.275 & & 0.250 & 0.148 & \\
\hline $\mathrm{TXB}_{2}$ & 0.433 & 0.027 & 0.051 & 0.212 & 0.200 & & 0.299 & 0.138 & & -0.247 & 0.153 & \\
\hline
\end{tabular}

*Pearson's correlation test model in non-PCOS patients. ${ }^{+}$Pearson's correlation test model in PCOS patients. ${ }^{* \ddagger}$ Multivariant linear regression model in non-PCOS patients. ${ }^{\ddagger}$ Multivariant linear regression model in PCOS patients.

(8,9-DHET and 11,12-DHET) in PCOS patients when compared with non-obese control.

We previously reported the diminished AA metabolites in the serum of PCOS patients (Li et al. 2017) and elevated COX-2 expression in ovaries of PCOS rats (Huang et al. 2018). Here we further clarified that AA metabolites via COX-2 were also increased in FF of PCOS patients, which was consistent with the rat model results. While the levels of AA and its downstream metabolites in serum reflect the AA metabolism in the whole body, the AA in the ovaries of PCOS rats and in the FF of PCOS patients has more profound effects on the local metabolism and biological consequence in the ovaries. These differences between serum and FF in PCOS patients further indicate the important role of local AA metabolism in PCOS patients. Furthermore, we also clarified the elevation of AA metabolites via P450 $0_{\text {еро }}$ in PCOS follicular fluid. Although the function of AA metabolites via $\mathrm{P} 40_{\text {epo }}$ has not been clarified, our finding provides a new insight in the pathophysiology and potential treatment of PCOS patients in the future.

PGs played important roles in many processes of reproduction. For example, $\mathrm{PGE}_{2}$ is an autocrine and paracrine mediator of oocyte maturation and cumulus expansion. $\mathrm{PGE}_{2}$ participates in cumulus-oocyte coupling and cumulus cell expansion (Calder et al. 2001), thus enhancing the release of luteinizing hormone-releasing hormone (LHRH) from the hypothalamus (Kim \& Ramirez 1986). On the other hand, an increased $\mathrm{PGE}_{2}$ level in the FF may delay follicle development, and a very high $\mathrm{PGE}_{2}$ level may be detrimental to oocyte maturation (Marei et al. 2010, Wang et al. 2012). Along with $\mathrm{PGE}_{2 \text {, }}$ $\mathrm{PGF}_{2 \alpha}$ is critical for ovulation because it increases collagenolysis and ovarian contractility. The increase in the $\mathrm{PGF}_{2 \alpha}$ level in the ovary may serve to overcome the inability to ovulate in patients with PCOS. Besides $\mathrm{PGE}_{2}$ and $\mathrm{PGF}_{2 \alpha}$ we also found that $\mathrm{PG}_{2}$ was significantly elevated in PCOS patients, and it was closely correlated with serum insulin and testosterone. However, the role of $P G J_{2}$ in granulosa cells remains to be studied. $P G J_{2}$ is not stable in vivo, and it could be easily transformed to cyclopentenone PGs, including 9-deoxy- $\Delta 9,12,13,14-$ dihydro $\mathrm{PGD}_{2}\left(\triangle 12-\mathrm{PGJ}_{2}\right)$ and $15 \mathrm{~d}-\mathrm{PGJ}_{2}$ (Narumiya \& Fukushima 1985). $15 \mathrm{~d}_{-} \mathrm{PGJ}_{2}$ is an endogenous ligand of peroxisome proliferator-activated receptor gamma (PPAR $\gamma$ ) that regulates inflammation (Jiang et al. 1998, Valledor \& Ricote 2004), granulosa cell proliferation (Chen et al. 2015), steroid hormone biosynthesis (Komar 2005), and fibrosis (Iwase et al. 2009). By using 'one follicle - one retrieved oocyte - one resulting embryo' approach, Ciepiela et al. found that elevated concentrations of AA- derived metabolites in FF at the time of oocyte retrieval significantly decreased the ability of oocytes to form pronuclei after ICSI in non-PCOS patients (Ciepiela et al. 2015). The specific function of PGs in IVF/ICSI still needs further exploration.

Both hyperandrogenism and hyperinsulinemia are two common characteristics in PCOS patients 

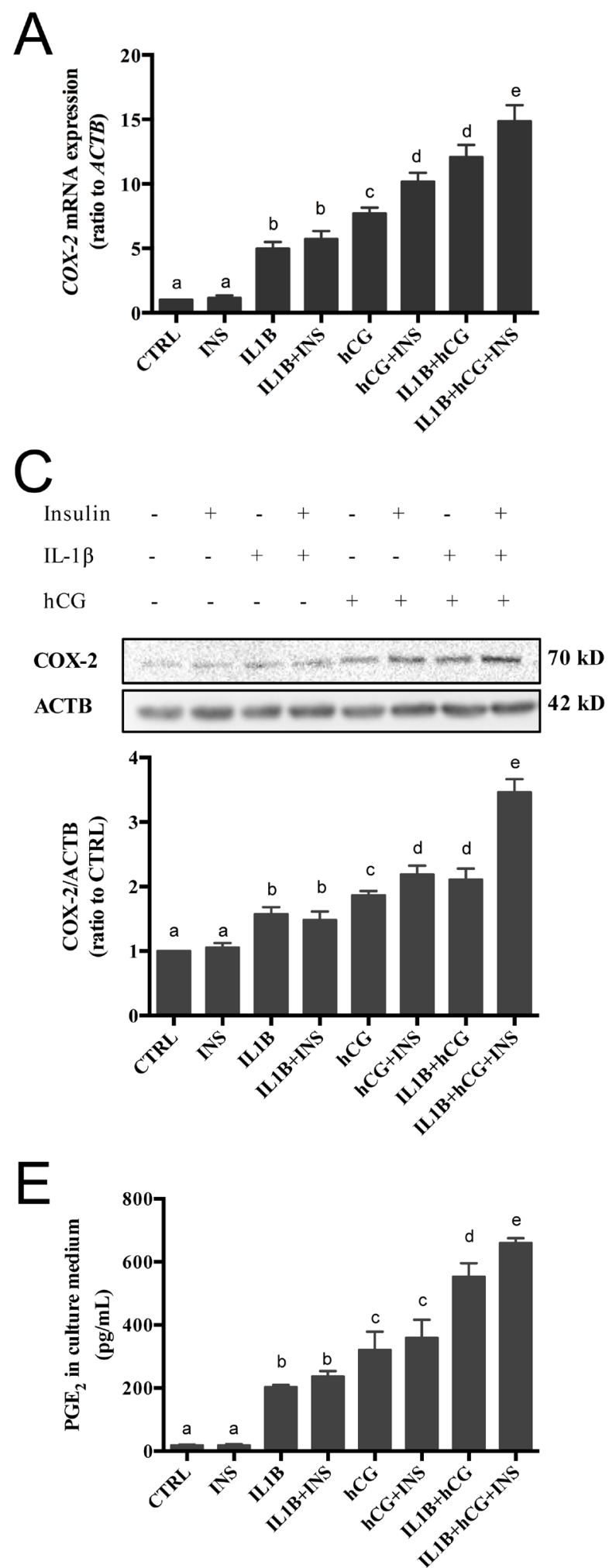

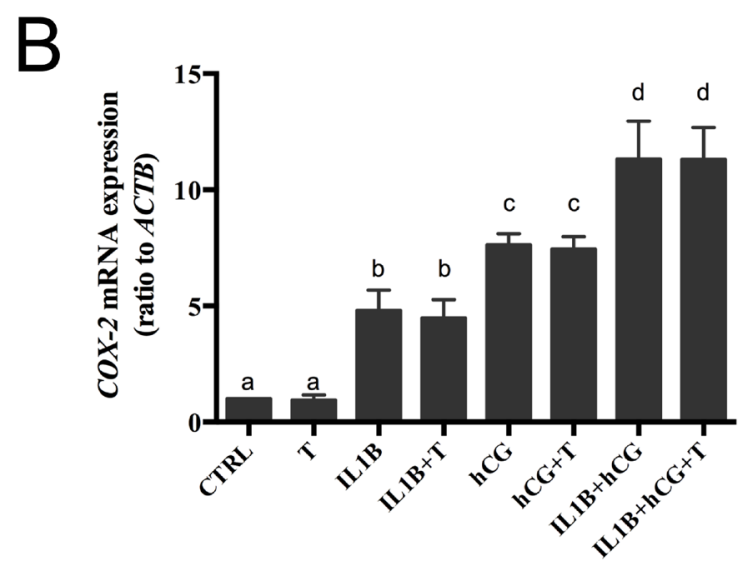

D

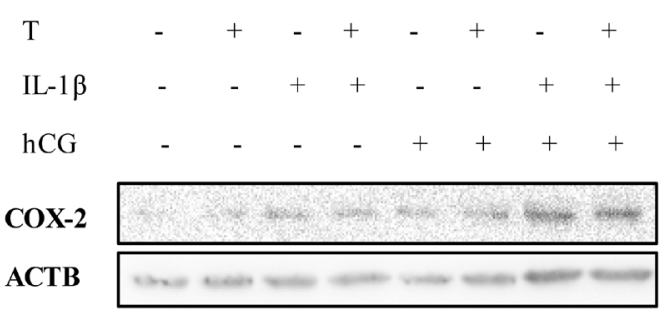

$70 \mathrm{kD}$

$42 \mathrm{kD}$

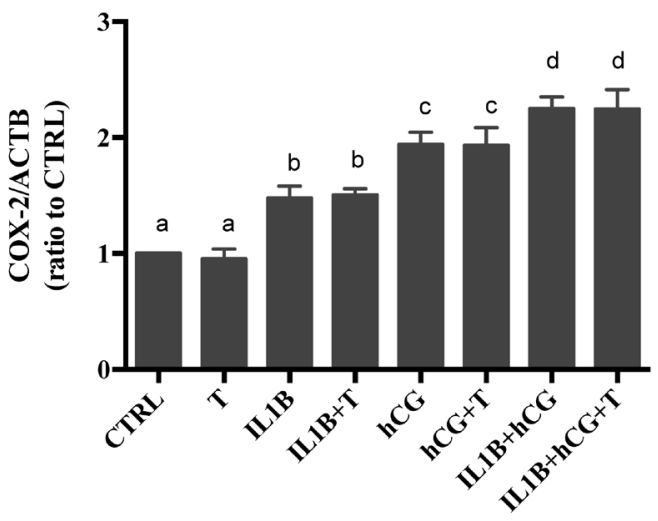

E

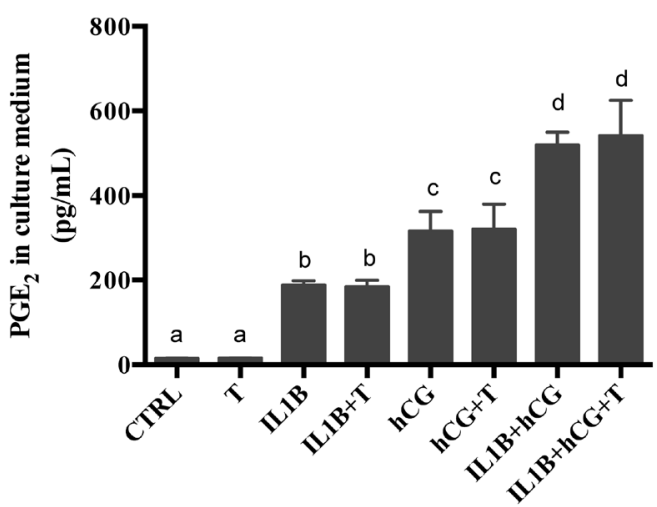

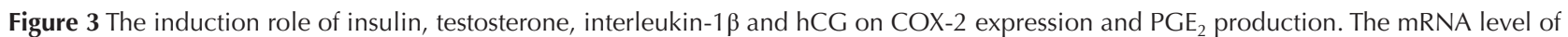
COX-2 with treatment of insulin, interleukin- $1 \beta$ and hCG (A). The mRNA level of COX-2 with treatment of testosterone, interleukin-1 $\beta$ and hCG (B). The protein level of COX-2 with treatment of testosterone, interleukin-1 $\beta$ and hCG (C). The $\mathrm{PGE}_{2}$ concentration of culture medium of granulosa cells treated with testosterone, interleukin-1 $\beta$ and hCG (D). The medicine concentrations are as followed: insulin (100 nM), testosterone $(100 \mathrm{nM})$, hCG $(10 \mathrm{IU} / \mathrm{L})$ and interleukin $1 \beta(1 \mathrm{ng} / \mathrm{mL})$. Data are represented as mean \pm S.E.M. $n=4$ for each experiment. Values with a different letter above are statistically significantly different $(P<0.05)$. CTRL, control; INS, insulin; T, testosterone; IL1B, interleukin-1 $\beta$. 
(Diamanti-Kandarakis \& Dunaif 2012). Insulin resistance, characterized by compensatory hyperinsulinemia, is observed not only in peripheral tissues but also in ovarian granulosa cells in PCOS patients (Zhu et al. 2016). Previous studies have explored the role of insulin on COX-2 in other tissues but the results remain controversial. Some studies demonstrated that insulin could increase COX-2 expression, and might further augment the IL-1 $\beta$-induced COX-2 expression and $\mathrm{PGE}_{2}$ production (Martins et al. 2010, Song et al. 2014). Meanwhile, there were also some studies that clarified the reduction role of insulin on COX-2 expression (Martins et al. 2008, Xu et al. 2018). These findings led us to speculate whether insulin and androgen were correlated with the increased AA metabolites.

Our study revealed that AA metabolites via COX-2 pathway $\left(\mathrm{PGE}_{2}, \mathrm{PGF}_{2 \alpha^{\prime}}\right.$ and $\left.P \mathrm{PJ}_{2}\right)$ were significantly related with serum insulin and testosterone levels in the multivariate linear regression model, which indicates hyperinsulinemia and hyperandrogenism in PCOS might contribute to the enhanced AA metabolism through COX-2 pathway. Multivariant linear regression analysis showed that AA metabolites generated via $\mathrm{COX}\left(\mathrm{PG}_{2}, \mathrm{PGD}_{2}\right.$, and $\mathrm{PGE}_{2}$ ) in $\mathrm{PCOS}$ group were significantly associated with basal fasting insulin level, not testosterone, after adjusting for basal $\mathrm{LH}$ and $\mathrm{BMI}$ in the groups separately. To clarify whether testosterone or insulin regulates $\mathrm{COX}_{2}$ and $\mathrm{PGE}_{2}$ expression, we designed an in vitro experiment using primary isolated granulosa cell.

Considering the chronic inflammation state of PCOS patients and the application of hCG in supra-ovulation, the in vitro study mimics the collaboration role of the inflammatory PCOS state. We treated granulosa cells together with IL-1 $\beta$, hCG, testosterone and insulin to figure out their induction role on COX-2. IL-1 $\beta$ and hCG are known to induce COX-2 expression and PGs production in many different cells and tissues. Our study revealed that both IL-1 $\beta$ and hCG could significantly induce the expression of COX-2 and the combined treatment of IL-1 $\beta$ and hCG could further increase the expression of COX-2. However, neither insulin nor testosterone had an induction role on the expression of COX-2 without the IL-1 $\beta$ and hCG treatment. Insulin, but not testosterone, could enhance the IL-1 $\beta$ - and hCGinduced COX-2 expression in granulosa cells. These in vitro findings demonstrated the hyperinsulinemia in PCOS might be a causing factor in the increased prostaglandins in follicular fluid. Although we previously reported that androgens downregulate the levels of COX metabolites in the serum of patients with PCOS, there are several important differences between the previous and present studies. Firstly, the levels of AA metabolites in serum are contributed from many different cells, such as hepatocytes, endotheliocytes, peripheral blood granulocytes, and mononuclear cells, whereas only ovarian cells contribute to the levels of these metabolites in the FF. The AA metabolites in follicular fluid specifically reflect local ovarian state. Second, the patients in this study underwent gonadotropin stimulation, which upregulated the levels of PGs. Hyperinsulinemia could exaggerate the induction role of inflammation and $\mathrm{LH}$ on COX-2 expression and stimulate the granulosa cells producing more PGs, $\mathrm{PGE}_{2}$ for example. Consistent with the correlation analysis, in vitro study provided evidence for the enhancement of insulin on the IL-1 $\beta$ and hCG-induced COX-2 expression. Therefore, we put forward the elevated AA metabolites in PCOS follicular fluid and its close correlation with hyperinsulinemia for the first time.

\section{Limitation}

There are some limitations in this study. (1) Since the FF in this study are collected from more than one follicle, which may have been sub-par to the one follicle-one retrieved oocyte-one resulting embryo design. (2) Previously, we reported that there was no significant difference in serum AA concentration between lean control group and lean PCOS group (Li et al. 2017). In this study, there was no change in the concentration of AA in follicular fluid, but its metabolism was higher in non-obese PCOS group than BMI-matched control group, suggesting a high transfer of AA from circulation or increased hydrolysis of local phospholipids in the ovary. But lack of serum AA and its metabolites is a real shortage of this study. (3) We have not directly detected the activity of COX in primary isolated granulosa cells from PCOS patients and control. (4) Relatively small sample sizes, large data variations, may weaken statistical efficiency. (5) The in vitro experiment could not exactly mimic the in vivo effects of testosterone. Firstly, testosterone may exert its physiological effects through different signaling pathways (androgen receptor or membrane receptors) depending on the target tissue and microenvironments in the body (Goldman et al. 2017). Meanwhile, testosterone could metabolite to estrogen and have complicated functions in vivo. In vitro cell experiments could not fully mimic the in vivo condition and exert the actual action of testosterone in the body. Second, the metabolites or hormones in the follicular fluid reflect the changes in testosterone after it acts on various cells in ovarian tissue (e.g. theca cell, granulosa cell, etc.), while in vitro experiments only reflect the secretion changes of primary isolated granulosa cells after the stimulation of testosterone.

In conclusion, we demonstrated that under gonadotropin stimulation, the levels of AA metabolites generated via the COX-2 were elevated in the FF of patients with PCOS and for the first time reported the elevation of AA metabolites via $\mathrm{P} 450_{\text {epo }}$ in PCOS patients. We also suggest the possible role of hyperinsulinemia on AA metabolism via COX-2 pathway in PCOS patients. Further studies are needed to define the potential mechanism and to further characterize the relationship 
between PGs and follicle development in patients that undergo IVF. These results provide new insights on how to improve embryo health and IVF outcomes.

\section{Supplementary materials}

This is linked to the online version of the paper at https://doi.org/10.1530/REP-19-0136.

\section{Declaration of interest}

The authors declare that there is no conflict of interest that could be perceived as prejudicing the impartiality of the research reported.

\section{Funding}

This study was supported by the National Key R\&D Program of China (No. 2017 YFC1001403 to Y S), National Natural Science Foundation of China under Grant (No. 81571499 to $Y$ S, No. 81471029 to S L, No. 81671518 to W L), Clinical skills improvement project of major disorders hospital development center of Shanghai (No. 16CR1022A to Y S) and Shanghai Municipal Education Commission-Gaofeng Clinical Medicine Grant Support (Grant 20161413 to Y S).

\section{Author contribution statement}

Y S and $\mathrm{H} Y$ designed the study. Q Z, R H, Y L, J Y and W L collected patients' specimens and related information. $\mathrm{S}$ L, J $\mathrm{Q}, \mathrm{YT}$ and $\mathrm{HZ}$ contributed to conducting the experiments and analyzing the data. S L, J Q and $\mathrm{HY}$ drafted and revised the paper. All authors reviewed the results and approved the final version of the manuscript.

\section{References}

Azziz R, Woods KS, Reyna R, Key TJ, Knochenhauer ES \& Yildiz BO 2004 The prevalence and features of the polycystic ovary syndrome in an unselected population. Journal of Clinical Endocrinology and Metabolism 89 2745-2749. (https://doi.org/10.1210/jc.2003-032046)

Boomsma CM, Eijkemans MJ, Hughes EG, Visser GH, Fauser BC \& Macklon NS 2006 A meta-analysis of pregnancy outcomes in women with polycystic ovary syndrome. Human Reproduction Update 12 673-683. (https://doi.org/10.1093/humupd/dml036)

Buczynski MW, Dumlao DS \& Dennis EA 2009 Thematic Review Series: proteomics. An integrated omics analysis of eicosanoid biology. Journal of Lipid Research 50 1015-1038. (https://doi.org/10.1194/jlr.R900004-JLR200)

Calder MD, Caveney AN, Westhusin ME \& Watson AJ 2001 Cyclooxygenase-2 and prostaglandin $\mathrm{E}(2)(\mathrm{PGE}(2))$ receptor messenger RNAs are affected by bovine oocyte maturation time and cumulusoocyte complex quality, and PGE(2) induces moderate expansion of the bovine cumulus in vitro. Biology of Reproduction 65 135-140. (https:// doi.org/10.1095/biolreprod65.1.135)

Chen MJ, Chou CH, Chen SU, Yang WS, Yang YS \& Ho HN 2015 The effect of androgens on ovarian follicle maturation: dihydrotestosterone suppress $\mathrm{FSH}$-stimulated granulosa cell proliferation by upregulating PPARgamma-dependent PTEN expression. Scientific Reports 518319. (https://doi.org/10.1038/srep18319)

Ciepiela P, Baczkowski T, Drozd A, Kazienko A, Stachowska E \& Kurzawa R 2015 Arachidonic and linoleic acid derivatives impact oocyte ICSI fertilization - a prospective analysis of follicular fluid and a matched oocyte in a 'one follicle-one retrieved oocyte-one resulting embryo' investigational setting. PLOS ONE 10 e0119087. (https://doi. org/10.1371/journal.pone.0119087)

Deems R, Buczynski MW, Bowers-Gentry R, Harkewicz R \& Dennis EA 2007 Detection and quantitation of eicosanoids via high performance liquid chromatography-electrospray ionization-mass spectrometry. Methods in Enzymology 432 59-82. (https://doi.org/10.1016/S0076-6879(07)32003-X)

Diamanti-Kandarakis E \& Dunaif A 2012 Insulin resistance and the polycystic ovary syndrome revisited: an update on mechanisms and implications. Endocrine Reviews 33 981-1030. (https://doi.org/10.1210/ er.2011-1034)

Gerard N, Loiseau S, Duchamp G \& Seguin F 2002 Analysis of the variations of follicular fluid composition during follicular growth and maturation in the mare using proton nuclear magnetic resonance (1H NMR). Reproduction 124 241-248. (https://doi.org/10.1530/rep.0.1240241)

Goldman AL, Bhasin S, Wu FCW, Krishna M, Matsumoto AM \& Jasuja R 2017 A reappraisal of testosterone's binding in circulation: physiological and clinical implications. Endocrine Reviews 38 302-324. (https://doi. org/10.1210/er.2017-00025)

Han X, Yang J, Cheng H, Ye H \& Gross RW 2004 Toward fingerprinting cellular lipidomes directly from biological samples by two-dimensional electrospray ionization mass spectrometry. Analytical Biochemistry 330 317-331. (https://doi.org/10.1016/j.ab.2004.04.004)

Han X, Yang K, Cheng H, Fikes KN \& Gross RW 2005 Shotgun lipidomics of phosphoethanolamine-containing lipids in biological samples after one-step in situ derivatization. Journal of Lipid Research 46 1548-1560. (https://doi.org/10.1194/jlr.D500007-JLR200)

Heijnen EM, Eijkemans MJ, Hughes EG, Laven JS, Macklon NS \& Fauser BC 2006 A meta-analysis of outcomes of conventional IVF in women with polycystic ovary syndrome. Human Reproduction Update 12 13-21. (https://doi.org/10.1093/humupd/dmi036)

Homburg R, Berkowitz D, Levy T, Feldberg D, Ashkenazi J \& BenRafael Z 1993 In vitro fertilization and embryo transfer for the treatment of infertility associated with polycystic ovary syndrome. Fertility and Sterility 60 858-863. (https://doi.org/10.1016/s0015-0282(16)56287-6)

Huang Y, Zhu M, Li Z, Sa R, Chu Q, Zhang Q, Zhang H, Tang W, Zhang M \& Yin H 2014 Mass spectrometry-based metabolomic profiling identifies alterations in salivary redox status and fatty acid metabolism in response to inflammation and oxidative stress in periodontal disease. Free Radical Biology and Medicine 70 223-232. (https://doi.org/10.1016/j. freeradbiomed.2014.02.024)

Huang R, Xue X, Li S, Wang Y, Sun Y, Liu W, Yin H \& Tao T 2018 Alterations of polyunsaturated fatty acid metabolism in ovarian tissues of polycystic ovary syndrome rats. Journal of Cellular and Molecular Medicine 22 3388-3396. (https://doi.org/10.1111/jcmm.13614)

Iwase A, Goto M, Harata T, Takigawa S, Nakahara T, Suzuki K, Manabe S \& Kikkawa F 2009 Insulin attenuates the insulin-like growth factor-I (IGF-I)-Akt pathway, not IGF-I-extracellularly regulated kinase pathway, in luteinized granulosa cells with an increase in PTEN. Journal of Clinical Endocrinology and Metabolism 94 2184-2191. (https://doi.org/10.1210/ jc.2008-1948)

Jiang C, Ting AT \& Seed B 1998 PPAR-gamma agonists inhibit production of monocyte inflammatory cytokines. Nature 391 82-86. (https://doi. org/10.1038/34184)

Jungheim ES, Macones GA, Odem RR, Patterson BW, Lanzendorf SE, Ratts VS \& Moley KH 2011 Associations between free fatty acids, cumulus oocyte complex morphology and ovarian function during in vitro fertilization. Fertility and Sterility 95 1970-1974. (https://doi. org/10.1016/j.fertnstert.2011.01.154)

Khajeh M, Rahbarghazi R, Nouri M \& Darabi M 2017 Potential role of polyunsaturated fatty acids, with particular regard to the signaling pathways of arachidonic acid and its derivatives in the process of maturation of the oocytes: contemporary review. Biomedicine and Pharmacotherapy 94 458-467. (https://doi.org/10.1016/j. biopha.2017.07.140)

Kim K \& Ramirez VD 1986 Effects of prostaglandin E2, forskolin and cholera toxin on cAMP production and in vitro $\mathrm{LH}-\mathrm{RH}$ release from the rat hypothalamus. Brain Research 386 258-265. (https://doi. org/10.1016/0006-8993(86)90162-9)

Kim YS, Kim MS, Lee SH, Choi BC, Lim JM, Cha KY \& Baek KH 2006 Proteomic analysis of recurrent spontaneous abortion: identification 
of an inadequately expressed set of proteins in human follicular fluid. Proteomics 6 3445-3454. (https://doi.org/10.1002/pmic.200500775)

Kolialexi A, Mavrou A, Spyrou G \& Tsangaris GT 2008 Mass spectrometrybased proteomics in reproductive medicine. Mass Spectrometry Reviews 27 624-634. (https://doi.org/10.1002/mas.20181)

Komar CM 2005 Peroxisome proliferator-activated receptors (PPARs) and ovarian function - implications for regulating steroidogenesis, differentiation, and tissue remodeling. Reproductive Biology and Endocrinology 3 41. (https://doi.org/10.1186/1477-7827-3-41)

Leroy JL, Rizos D, Sturmey R, Bossaert P, Gutierrez-Adan A, Van Hoeck V, Valckx S \& Bols PE 2011 Intrafollicular conditions as a major link between maternal metabolism and oocyte quality: a focus on dairy cow fertility. Reproduction, Fertility, and Development 24 1-12. (https://doi. org/10.1071/RD11901)

Li R, Zhang Q, Yang D, Li S, Lu S, Wu X, Wei Z, Song X, Wang X, Fu S et al. 2013 Prevalence of polycystic ovary syndrome in women in China: a large community-based study. Human Reproduction 28 2562-2569. (https://doi.org/10.1093/humrep/det262)

Li S, Chu Q, Ma J, Sun Y, Tao T, Huang R, Liao Y, Yue J, Zheng J, Wang L et al. 2017 Discovery of novel lipid profiles in PCOS: do insulin and androgen oppositely regulate bioactive lipid production? Journal of Clinical Endocrinology and Metabolism 102 810-821. (https://doi. org/10.1210/jc.2016-2692)

Lu J, Chen B, Chen T, Guo S, Xue X, Chen Q, Zhao M, Xia L, Zhu Z, Zheng L et al. 2017 Comprehensive metabolomics identified lipid peroxidation as a prominent feature in human plasma of patients with coronary heart diseases. Redox Biology 12 899-907. (https://doi.org/10.1016/j. redox.2017.04.032

Marei WF, Wathes DC \& Fouladi-Nashta AA 2010 Impact of linoleic acid on bovine oocyte maturation and embryo development. Reproduction 139 979-988. (https://doi.org/10.1530/REP-09-0503)

Marions L \& Danielsson KG 1999 Expression of cyclo-oxygenase in human endometrium during the implantation period. Molecular Human Reproduction 5 961-965. (https://doi.org/10.1093/molehr/5.10.961)

Martins JO, Ferracini M, Ravanelli N, Landgraf RG \& Jancar S 2008 Insulin suppresses LPS-induced iNOS and COX-2 expression and NFkappaB activation in alveolar macrophages. Cellular Physiology and Biochemistry 22 279-286. (https://doi.org/10.1159/000149806)

Martins JO, Wittlin BM, Anger DB, Martins DO, Sannomiya P \& Jancar S 2010 Early phase of allergic airway inflammation in diabetic rats: role of insulin on the signaling pathways and mediators. Cellular Physiology and Biochemistry 26 739-748. (https://doi.org/10.1159/000322341)

Matoba S, Bender K, Fahey AG, Mamo S, Brennan L, Lonergan P \& Fair T 2014 Predictive value of bovine follicular components as markers of oocyte developmental potential. Reproduction, Fertility, and Development 26 337-345. (https://doi.org/10.1071/RD13007)

Narumiya S \& Fukushima M 1985 delta 12-prostaglandin J2, an ultimate metabolite of prostaglandin D2 exerting cell growth inhibition. Biochemical and Biophysical Research Communications 127 739-745. (https://doi.org/10.1016/s0006-291x(85)80005-x)

Revelli A, Delle Piane L, Casano S, Molinari E, Massobrio M \& Rinaudo P 2009 Follicular fluid content and oocyte quality: from single biochemical markers to metabolomics. Reproductive Biology and Endocrinology 7 40. (https://doi.org/10.1186/1477-7827-7-40)

Robker RL, Akison LK, Bennett BD, Thrupp PN, Chura LR, Russell DL, Lane M \& Norman RJ 2009 Obese women exhibit differences in ovarian metabolites, hormones, and gene expression compared with moderateweight women. Journal of Clinical Endocrinology and Metabolism 94 1533-1540. (https://doi.org/10.1210/jc.2008-2648)

Rodgers RJ \& Irving-Rodgers HF 2010 Formation of the ovarian follicular antrum and follicular fluid. Biology of Reproduction 82 1021-1029. (https://doi.org/10.1095/biolreprod.109.082941)

Rotterdam ESHRE/ASRM-Sponsored PCOS Consensus Workshop Group 2004 Revised 2003 consensus on diagnostic criteria and long-term health risks related to polycystic ovary syndrome. Fertility and Sterility 81 19-25. (https://doi.org/10.1016/j.fertnstert.2003.10.004)

Schaiff WT, Carlson MG, Smith SD, Levy R, Nelson DM \& Sadovsky Y 2000 Peroxisome proliferator-activated receptor-gamma modulates differentiation of human trophoblast in a ligand-specific manner. Journal of Clinical Endocrinology and Metabolism 85 3874-3881. (https://doi. org/10.1210/jcem.85.10.6885)
Schweigert FJ, Gericke B, Wolfram W, Kaisers U \& Dudenhausen JW 2006 Peptide and protein profiles in serum and follicular fluid of women undergoing IVF. Human Reproduction 21 2960-2968. (https://doi. org/10.1093/humrep/del257)

Shi Y, Wei D, Liang X, Sun Y, Liu J, Cao Y, Zhang B, Legro RS, Zhang H \& Chen ZJ 2014 Live birth after fresh embryo transfer vs elective embryo cryopreservation/frozen embryo transfer in women with polycystic ovary syndrome undergoing IVF (FreFro-PCOS): study protocol for a multicenter, prospective, randomized controlled clinical trial. Trials 15 154. (https://doi.org/10.1186/1745-6215-15-154)

Song NY, Na HK, Baek JH \& Surh YJ 2014 Docosahexaenoic acid inhibits insulin-induced activation of sterol regulatory-element binding protein 1 and cyclooxygenase-2 expression through upregulation of SIRT1 in human colon epithelial cells. Biochemical Pharmacology 92 142-148. (https://doi.org/10.1016/j.bcp.2014.08.030)

Sorensen AE, Wissing ML, Englund AL \& Dalgaard LT 2016 MicroRNA species in follicular fluid associating with polycystic ovary syndrome and related intermediary phenotypes. Journal of Clinical Endocrinology and Metabolism 101 1579-1589. (https://doi.org/10.1210/jc.2015-3588)

Teede H, Deeks A \& Moran L 2010 Polycystic ovary syndrome: a complex condition with psychological, reproductive and metabolic manifestations that impacts on health across the lifespan. BMC Medicine 8 41. (https:// doi.org/10.1186/1741-7015-8-41)

Tokugawa Y, Kunishige I, Kubota Y, Shimoya K, Nobunaga T, Kimura T, Saji F, Murata Y, Eguchi N, Oda H et al. 1998 Lipocalin-type prostaglandin $\mathrm{D}$ synthase in human male reproductive organs and seminal plasma. Biology of Reproduction 58 600-607. (https://doi. org/10.1095/biolreprod58.2.600)

Valledor AF \& Ricote M 2004 Nuclear receptor signaling in macrophages. Biochemical Pharmacology 67 201-212. (https://doi.org/10.1016/j. bcp.2003.10.016)

Von Wald T, Monisova Y, Hacker MR, Yoo SW, Penzias AS, Reindollar RR \& Usheva A 2010 Age-related variations in follicular apolipoproteins may influence human oocyte maturation and fertility potential. Fertility and Sterility 93 2354-2361. (https://doi.org/10.1016/j.fertnstert.2008.12.129)

Wang J, Shen XX, Huang XH \& Zhao ZM 2012 Follicular fluid levels of prostaglandin E2 and the effect of prostaglandin E2 on steroidogenesis in granulosa-lutein cells in women with moderate and severe endometriosis undergoing in vitro fertilization and embryo transfer. Chinese Medical Journal 125 3985-3990.

Wang Y, Armando AM, Quehenberger O, Yan C \& Dennis EA 2014 Comprehensive ultra-performance liquid chromatographic separation and mass spectrometric analysis of eicosanoid metabolites in human samples. Journal of Chromatography A 1359 60-69. (https://doi. org/10.1016/j.chroma.2014.07.006)

Xu J, Cao L, Suo Y, Xu X, Sun H, Xu S, Zhu X, Yu H \& Cao W 2018 Chitosan-microcapsulated insulin alleviates mesenteric microcirculation dysfunction via modulating COX-2 and VCAM-1 expression in rats with diabetes mellitus. International Journal of Nanomedicine 13 6829-6837. (https://doi.org/10.2147/IJN.S174030)

Yang J, Schmelzer K, Georgi K \& Hammock BD 2009 Quantitative profiling method for oxylipin metabolome by liquid chromatography electrospray ionization tandem mass spectrometry. Analytical Chemistry 81 8085-8093. (https://doi.org/10.1021/ac901282n)

Zhu Q, Zuo R, He Y, Wang Y, Chen ZJ, Sun Y \& Sun K 2016 Local regeneration of cortisol by 11 beta-HSD1 contributes to insulin resistance of the granulosa cells in PCOS. Journal of Clinical Endocrinology and Metabolism 101 2168-2177. (https://doi.org/10.1210/jc.2015-3899)

Zhuang J, Liu Y, Xu L, Liu X, Zhou L, Tang L, Kang D, Guo W, He M, Yang F et al. 2014 Prevalence of the polycystic ovary syndrome in female residents of Chengdu, China. Gynecologic and Obstetric Investigation 77 217-223. (https://doi.org/10.1159/000358485)

Received 28 March 2019

First decision 8 May 2019

Revised manuscript received 17 November 2019

Accepted 26 November 2019 